\title{
Quantifying Carbon Monoxide Emissions on the Scale of Large Wildfires
}

\section{Rainer Volkamer ( $\square$ Rainer.Volkamer@Colorado.EDU)}

University of Colorado https://orcid.org/0000-0002-0899-1369

\section{Megan Bela}

CIRES \& NOAA/ESRL/CSL

\section{Natalie Kille}

CIRES, Chemistry \& ATOC https://orcid.org/0000-0001-7116-8132

\section{Stuart McKeen}

NOAA Earth System Research Laboratory

\section{Ravan Ahmadov}

NOAA Earth System Research Laboratory

\section{Eric James}

CIRES \& NOAA/ESRL/GSL

\section{Gabriel Pereira}

Universidade Federal de Sao Joao del-Rei \& Universidad de Sao Paulo https://orcid.org/0000-00022093-9942

\section{Chris Schmidt}

Cooperative Institute for Meteorological Satellite Studies, Space Science and Engineering Center, University of Wisconsin-Madison

\section{R Pierce}

Space Science and Engineering Center, University of Wisconsin-Madison

\section{Susan O'Neill}

Pacific Wildland Fire Sciences Laboratory, US Forest Service Pacific Northwest Research Station

\section{Xiaoyang Zhang}

South Dakota State University

\section{Shobha Kondragunta}

NOAA/NESDIS Center for Satellite Applications and Research

\section{Christine Wiedinmyer}

CIRES, University of Colorado Boulder

\section{Article}

Keywords: wildfires, air quality, $\mathrm{CO}$ emissions, northern California 
Posted Date: August 26th, 2020

DOl: https://doi.org/10.21203/rs.3.rs-59115/v1

License: (c) (i) This work is licensed under a Creative Commons Attribution 4.0 International License. Read Full License 


\section{Quantifying Carbon Monoxide Emissions on the Scale of Large Wildfires}

2 M.M. Bela ${ }^{1,2, *}$, N. Kille ${ }^{1,3,4, *}$, S. A. McKeen ${ }^{1,2}$, R. Ahmadov ${ }^{1,5}$, E. James ${ }^{1,5}$, G. Pereira ${ }^{6,7}$, C.

3 Schmidt $^{8}$, R.B. Pierce ${ }^{9}$, S.M. O'Neill ${ }^{10}$, X. Zhang ${ }^{11}$, S. Kondragunta ${ }^{12}$, C. Wiedinmyer ${ }^{1}$, and R.

4 Volkamer ${ }^{1,3,4, *}$

${ }^{1}$ Cooperative Institute for Research in Environmental Sciences (CIRES), University of Colorado Boulder, 216 UCB, Boulder, CO, 80309, USA

${ }^{2}$ NOAA ESRL Chemical Sciences Laboratory, 325 Broadway, Boulder, CO, 80305, USA

${ }^{3}$ Department of Chemistry, University of Colorado Boulder, Cristol Chemistry, 215 UCB, Boulder, CO, 80309-0215, USA

${ }^{4}$ Department of Atmospheric and Oceanic Sciences, University of Colorado Boulder, 311 UCB, Boulder, CO 80309-0311, USA

${ }^{5}$ NOAA ESRL Global Systems Laboratory, 325 Broadway, Boulder, CO, 80305, USA

${ }^{6}$ Departamento de Geociências, Universidade Federal de São João del-Rei, Praça Frei Orlando, 170, Centro, São João del-Rei, Minas Gerais, CEP: 36307-352, Brasil

${ }^{7}$ Programa de Pós-graduação em Geografia Física, Universidade de São Paulo, R. da Reitoria, 374 - Cidade Universitária, Butantã, São Paulo - SP, 05508-220, Brasil

${ }^{8}$ Cooperative Institute for Meteorological Satellite Studies, Space Science and Engineering Center, University of Wisconsin-Madison, 1225 W. Dayton St., Madison, WI, 53706, USA

${ }^{9}$ Space Science and Engineering Center, University of Wisconsin-Madison, 1225 W. Dayton St., Madison, WI, 53706, USA

${ }^{10}$ Pacific Wildland Fire Sciences Laboratory, US Forest Service Pacific Northwest Research Station, N. 34th Street, Seattle, WA 98103, USA.

${ }^{11}$ South Dakota State University, 1004 Campanile Ave, Brookings, SD, 57007, USA

12 NOAA/NESDIS Center for Satellite Applications and Research, 5825 University Research Ct, College Park, MD, 20740, USA

*These authors contributed equally to this work

Correspondence to: rainer.volkamer@colorado.edu 
5 Anthropogenic factors, such as ignitions, climate, and land use changes, are the primary

6 reason why the wildfire season today is three times longer than only twenty years ago, with

7 fires now burning year-round in the continental United States1. The quantities of fuel that

8 go up as smoke in the form of trace gases and aerosols affect public health ${ }^{2,3,4}$ and

9 ecosystems ${ }^{5}$, but are highly uncertain ${ }^{6,7,8,9}$ due to a lack of measurement techniques to

10 directly quantify wildfire emissions. Uncertain emissions contribute to errors in air quality

11 models ${ }^{10,11}$ used to forecast smoke impacts on public health in affected communities, and to

12 inform firefighting efforts. Here we show that destructive fires in northern California during

13 October 2017 emitted $2040 \pm 316$ tonnes $\mathrm{hr}^{-1}$ carbon monoxide (CO), which is more than ten

14 times larger than the emissions from all other anthropogenic CO pollution sources in the

15 entire state of California combined. An assessment of satellite-based emission inventories

16 reveals that the uncertainty in predicting pyrogenic $\mathrm{CO}$ emissions spans a factor of 83. Air

17 quality impacts in the form of ozone and fine particulate matter range from insignificant to

18 very severe (vary by two orders of magnitude), and scale with uncertain emissions caused

19 primarily by the different ecosystem classification among emission inventories. This

20 uncertainty is reduced to a factor of $\sim 2$ by our first $\mathrm{CO}$ mass flux measurements on the scale

21 of actual wildfires. We derive the conversion factor of satellite fire radiative energy to CO

22 emissions $\left(\alpha=73 \pm 11\right.$ to $\left.149 \pm 23 \mathrm{~g} \mathrm{CO} \mathrm{MJ}^{-1}\right)$ for savannah and extratropical forest fuels of

23 these fires, which is higher $(+\mathbf{3 0}$ to $+\mathbf{2 3 0} \%)$ than tabulated for these fuel types. Our results

24 help to improve future model predictions, and suggest an additional organic soil contribution

25 to emissions from wildfires in northern California. 


\section{Emission flux measurements}

27 The October 2017 fires near Santa Rosa in northern California (N. CA) were the second most

28 destructive fires to date in California ${ }^{12}$, killing 44 people $^{13}$, destroying nearly 9,000 structures ${ }^{13,14}$,

29 with reported losses of over $\$ 10$ billion $^{14}$, and resulting in the highest particulate matter $\left(\mathrm{PM}_{2.5}\right)$

30 levels recorded in the Bay Area since $1999^{15}$. The Tubbs fire, the largest of the Oct. 2017 N. CA

31 fires, which devastated the city of Santa Rosa, was started by a private electrical system ${ }^{16}$, and was

32 associated with an intense terrain-induced downslope windstorm ${ }^{17}$. Such windstorms, commonly

33 known as "Santa Ana" or "Diablo" winds, can be very destructive when driving fires and are

34 projected with climate change to extend the fire season later into the fall and winter ${ }^{17}$.

35 The Oct. 2017 N. CA fires are an example of fires with anthropogenic ignition sources and

36 their subsequent air quality impacts that are likely to increase due to a warmer and drier climate in

37 the Western U.S. during the $21^{\text {st }}$ century ${ }^{18,19,20,21}$. These trends combined with rising numbers of

38 humans living in the urban-wildland interface are likely to result in increases in population

39 exposure to fire activity ${ }^{22}$ and poor air quality episodes ${ }^{23}$. Long-term exposure to elevated $\mathrm{PM}_{2.5}$

40 may increase human susceptibility to respiratory diseases such as coronavirus (COVID-19) ${ }^{24,25}$.

41 The University of Colorado Airborne Solar Occultation Flux (CU AirSOF) instrument was

42 deployed to quantify the emission fluxes of the N. CA wildfires on Oct. 10, 2017. CU AirSOF

43 consists of a Fourier Transform Spectrometer installed on a research aircraft, and uses a digital

44 fast solar tracker to point directly at the sun to measure the total CO column above the aircraft at

45 mid-infrared wavelengths ${ }^{26,27}$. The SOF method has been used to quantify emissions from area

46 sources by mass balance ${ }^{28,29,30}$, but its potential to study wildfires remains largely unexplored. The

47 CU AirSOF instrument is a unique prototype, and optimized to quantify wildfire emissions due to 
48 its ability to capture the vertical column densities (VCD) of trace gases above the aircraft through

49 thick smoke plumes (see Methods). While satellite-based remote sensing has the advantage of

50 providing global coverage multiple times a day, satellite-based emission estimate methods may be

51 limited by saturation ${ }^{31,32}$ and their coarser spatial resolution. Lidar-based remote-sensing methods

52 may also saturate ${ }^{33}$, while in-situ methods do not fully characterize plume heterogeneity ${ }^{34,35}$.

53 Figure 1 shows the flight track of CU AirSOF downwind of the N. CA fires, color coded with

54 the CO VCD above the aircraft. The aircraft was positioned below the smoke plume during two

55 low altitude flight transects (T1 and T2) in the CA Central Valley between Sacramento and

56 Willows, two hours apart in the early to mid- afternoon local time. The plume was decoupled from

57 the ground, as is indicated by the aerosol vertical profile in Figure 2 (left panel). Figure 2 also

58 shows the spectral proof of $\mathrm{CO}$ detection by observing the uniquely specific fingerprint absorption

59 in the mid infrared region $\left(4215-4254 \mathrm{~cm}^{-1}\right)$ in solar spectra measured through the smoke plume.

60 The CO column signal varies by a factor of 2.7 at constant altitude ( $\sim 300 \mathrm{~m}$ above ground level)

61 inside and outside of the plume. The $\mathrm{CO}$ fingerprint absorption is well separated from other trace

62 gases that are fitted simultaneously in this spectral region (Extended Data Figure E1). Furthermore,

63 the CO column sensitivity of CU AirSOF above the aircraft is independent of altitude (Extended

64 Data Figure E2). Emission fluxes are calculated using the mass balance approach ${ }^{27,28,29}$, in which

65 VCD measurements and winds normal to the flight direction are integrated for each transect:

66

(1) $\quad F=\frac{M_{C O}}{N_{A}} \int \Delta V C D(s) \cdot \vec{u} \cdot \vec{n}(s) \cdot d s$

67 where $F$ is the emission flux $\left(\mathrm{g} \mathrm{s}^{-1}\right)$, Mco is the CO molar mass $\left(28 \mathrm{~g} \mathrm{~mol}^{-1}\right), \mathrm{N}_{\mathrm{A}}$ is Avogadro's 68 number $\left(\right.$ molec $\left.\mathrm{mol}^{-1}\right), \triangle V C D$ is the enhanced $\mathrm{CO}$ column observation in the plume over 69 background air $\left.(\text { molec cm})^{-2}\right), s$ is the aircraft path below the plume $(\mathrm{cm}), \vec{u}$ is the average measured 
70 wind vector within the plume $\left(\mathrm{cm} \mathrm{s}^{-1}\right)$, and $\vec{n}(s)$ is the normal vector orthogonal to the aircraft

71 direction.

72 Ours are the first $\mathrm{CO}$ emission flux quantifications using airborne $\mathrm{CO}$ column measurements

73 on the scale of actual wildfires.

\section{Simulating fire emission transport}

75 The N. CA fires emitted at least $2040 \pm 316$ tonnes $\mathrm{CO} \mathrm{hr}^{-1}$ on Oct. 10, 2017 (Table 1), which is

76 more than ten times larger than the daily mean anthropogenic $\mathrm{CO}$ pollution sources in the entire

77 state of CA combined (Extended Data Table E1). The CU AirSOF transect times were corrected

78 for atmospheric transport time from the source to compare the measured $\mathrm{CO}$ mass fluxes with

79 emission simulations using the Weather Research and Forecasting coupled with Chemistry (WRF-

80 Chem) model $^{36,37}$. CU AirSOF measurements during T1 (12:43 p.m. to 1:07 p.m. PDT) represent

81 emissions from 10:31 a.m. to 10:55 a.m. PDT, and T2 (2:52 to 3:15 p.m. PDT) represents

82 emissions from 12:22 p.m. to 12:45 p.m. PDT. While the uncertainty in the CO mass flux is rather

83 low (T1: $\pm 32.2 \%, \mathrm{~T} 2: \pm 15.5 \%$; see Methods, and Extended Data Table E2), comparison with the

84 modeled $\mathrm{CO}$ emissions is affected by the need to correct for atmospheric transport and by

85 uncertainties in the satellite-detected fire location, fire intensity (or Fire Radiative Power (FRP)),

86 and fire diurnal cycle $( \pm 16 \%$; see Methods, and Extended Data Table E2) used to model the fire

87 emissions.

88 In the WRF-Chem simulations, total pyrogenic emissions of $\mathrm{CO}$, other gases, and aerosols at

89 the T2 emissions time were scaled to the CU AirSOF CO T2 emission mass flux, and emissions

90 were distributed temporally either at a constant rate through the day, varying according to a 
91 climatological diurnal cycle ${ }^{38}$ (Extended Data Figure E3; see Methods), or varying according to

92 the observed Geostationary Operational Environmental Satellite (GOES)-16 FRP. WRF-Chem

93 simulations better reproduce the CU AirSOF observations of CO VCDs using emissions with a

94 climatological or GOES-16 based diurnal cycle rather than constant emissions throughout the day

95 (Figure 2). A constant emission rate results in $\mathrm{CO}$ accumulation in the model that results into

96 overestimates of the observed CO VCDs at the T2 aircraft sampling time (Figure 2). We conclude

97 that in order to best simulate the atmospheric state observed by CU AirSOF, the measured emission

98 flux needs to be constrained in the model, and the fire diurnal cycle must be properly constrained.

99 Air quality forecasting models typically use either a constant or climatological diurnal cycle,

100 though high temporal resolution satellite observations now exist (e.g. GOES-16 for the United

101 States).

102 Quantifying pyrogenic CO emissions

103 Figure 3 compares 8 different emission estimates from 6 different emission inventories with the

104 measured CU AirSOF CO mass fluxes. Model inventory diurnal mean values vary by a factor of

$105 \sim 83$ among the 8 separate estimates, which range from 79 to 6570 tonnes $\mathrm{hr}^{-1}$ (Extended Data

106 Table E1). The conversion factor of satellite derived fire radiative energy (FRE) to emissions, $\alpha$

107 ( $\mathrm{g} \mathrm{CO} \mathrm{MJ}^{-1}$, Table 1), was calculated as the ratios of the $\mathrm{CU}$ AirSOF fluxes (tonnes $\mathrm{CO} \mathrm{hr}^{-1}$ ) and 108 satellite FRE (15-minute average of Geostationary Operational Environmental Satellite (GOES)-

10916 observations, or Near Real Time (NRT) Moderate Resolution Imaging

110 Spectroradiometer (MODIS) point measurements, in $\mathrm{J} \mathrm{s}^{-1}$ ):

111

(2) $\alpha=c \cdot \frac{F_{C O}}{F R E}$ 
112 where $\mathrm{c}=2.78 \times 10^{8} \mathrm{~g}$ tonne $\mathrm{e}^{-1} \mathrm{hr} \mathrm{s}^{-1} \mathrm{~J} \mathrm{MJ}^{-1}$ is the unit conversion factor.

113 We are presenting the first $\alpha$ measurement on the scale of an actual wildfire. The CU AirSOF

114 fluxes increased from $\mathrm{T} 1$ to $\mathrm{T} 2$ by a factor of $\sim 5$, reflecting the intensifying fire activity. However,

115 the value of $\alpha$ differs by only $12 \%$ between the two transect sampling periods when using GOES-

11616 FRE (Table 1). MODIS FRE yields a different $\alpha$ from GOES-16 for the second transect time

117 by a factor of 2, pointing to the need to evaluate the satellite FRE data, and determine how to best

118 combine data from different satellites. For example, a comparison of FRP retrieved from MODIS

119 and Visible Infrared Imaging Radiometer Suite (VIIRS) revealed a strong dependence of FRP on

120 zenith viewing angle for MODIS but not VIIRS $^{39}$.

121 Independent of the FRP data source, $\alpha$ is measured to be higher than literature values for $\alpha$ for

122 the savannah and extratropical forest fuels identified in the International Geosphere-Biosphere

123 Programme vegetation dataset for the Oct. 2017 N. CA fires (Extended Data Table E3).

124 Interestingly, the $\alpha$ values for savannah and extratropical forest fuels are near identical, and lower

125 than observed. By comparison, extratropical forest fuels with high organic soil content show 3.4

126 times higher $\alpha$ values than without organic soil, and this range of $\alpha$ values fully encapsulates the

127 observations. Notably, $\alpha$ does not depend on assumptions about emission factors (EF), and the

128 comparison of different ecosystems is rather straightforward. We speculate that the higher

129 measured $\alpha$ values may be due to an additional organic soil contribution to the emissions from the

130 N. CA wildfires (Extended Data Table E3), though other factors are possible as well. According

131 to the Fuel Characteristic Classification System $(\mathrm{FCCS})^{40}$, one of the fuel types that the fires

132 burned was Redwood-Tanoak forest (see Methods), which contains organic soils and in the

133 Bluesky estimate accounts for $57 \%$ of the CO emissions on Oct. 10, 2017. 
134 Measuring $\alpha$ directly using the CU AirSOF method circumvents the uncertainty introduced in

135 satellite-based bottom-up emission methods that depend on vegetation classifications to calculate

136 emissions using EFs, fuel amounts per area, combustion completeness, and area burned ${ }^{41,42,43}$. For

137 the vegetation types relevant to this study (savannah and extratropical forest), CO EF values range

138 by a factor of 3 , and values of $\beta\left(\mathrm{kg}\right.$ dry matter $\left.\mathrm{MJ}^{-1}\right)$ used in top-down emissions inventories to

139 convert FRP to fuel burned vary by a factor of 2 (Extended Data Table E3). However, if the

140 vegetation type is unknown, $\mathrm{CO}$ EF values vary by a factor of 13 , and $\beta$ values by a factor of 45

141 (Extended Data Table E3). By contrast, FRE values from the GOES-16 and MODIS satellites at

142 the T2 emissions time vary by a factor of 2 (Table 1). The variability in emissions among

143 inventories (a factor of $\sim 83$ ) is significantly larger than the variations in FRE, $\beta$ or EF, particularly

144 if the correct ecosystem type is known. Thus, we infer that uncertain mass fluxes are primarily the

145 result of uncertain vegetation types, and to a lesser extent uncertain EFs, FREs, and diurnal cycles.

146 The conversion factor $\alpha$ is quantified for the first time on the scale of an actual wildfire, and

147 may help to improve estimates of air quality impacts.

\section{Sensitivity of air quality to emissions}

149 Model predicted air quality impacts from wildfires are particularly sensitive to emitted amounts of

$150 \mathrm{CO}$, which are tightly bound here, and therefore also used widely to represent emissions of other

151 pollutants. The change in boundary layer fine particulate matter $\left(\mathrm{PM}_{2.5}\right)$ and ozone $\left(\mathrm{O}_{3}\right)$ between

152 simulations with and without fire emissions at the T2 sampling time in the N. CA fire region was

153 calculated for WRF-Chem simulations with mean hourly CO emissions spanning the 2 orders of

154 magnitude predicted by the satellite-based inventories (Figure 3, Extended Data Figure E4). Figure

1553 shows that the production of $\mathrm{O}_{3}$ and $\mathrm{PM}_{2.5}$ averaged over the fire region exhibit a linear 
156 relationship with wildfire emissions on the regional scale. The mean boundary layer $\mathrm{PM}_{2.5}$ and $\mathrm{O}_{3}$

157 vary by 2 orders of magnitude in simulations with $\mathrm{CO}$ emissions spanning a similar range,

158 representative of the large spread among satellite-based inventories. By comparison, the effect of

159 a diurnal cycle is small. Only a factor of 2 change is seen in predicted $\mathrm{PM}_{2.5}$ and $\mathrm{O}_{3}$ between model

160 runs with constant emissions versus diurnally varied emissions. The predicted air quality impacts

161 from the N. CA fires range from negligible to severe, depending primarily on accurate estimates

162 of the amounts of fuel that go up in smoke. Our results highlight the importance of emissions

163 amounts, which can be experimentally constrained from CU AirSOF measurements, or estimated

164 based on ecosystem information for satellite-based methods, to improve predictions of the impact

165 of wildfires on air quality.

\section{Implications and outlook}

167 Our case study of the Oct. 10, 2017 N. CA wildfires illustrates the large impact of these fires on 168 air quality compared to statewide anthropogenic emission sources. Quantifying emission mass

169 fluxes by CU AirSOF is not limited to $\mathrm{CO}$, but can be extended to measurements of other trace

170 gases that absorb light at mid-infrared wavelengths. CU AirSOF provides an underused, yet

171 promising, new tool to investigate ecosystem-atmosphere linkages. The CU AirSOF

172 measurements enable the calculation of conversion factors $\alpha$ from satellite FRE, now provided at

173 high frequency by geostationary measurements, to emissions. $\alpha$ values determined from MODIS

174 versus GOES-16 for the Oct. 10, 2017 N. CA wildfires differ by a factor of 2 . This is due to

175 differences among FRE values retrieved by different polar-orbiting and geostationary satellites

176 that need to be reconciled in order to integrate the available satellite FRE sources to accurately

177 constrain emission predictions. 
178 The amounts of $\mathrm{O}_{3}$ and $\mathrm{PM}_{2.5}$ that are produced from wildfire emissions are highly uncertain.

179 North American wildfires have been observed to both efficiently generate and suppress $\mathrm{O}_{3}{ }^{44}$.

180 Current research and operational air quality forecasting models tend to overestimate $\mathrm{O}_{3}$ production

181 from wildfires ${ }^{45}$. Better constraints on $\alpha$ may lead to improved operational air quality model

182 predictions of both $\mathrm{O}_{3}$ and $\mathrm{PM}_{2.5}$ used to provide warnings to affected communities and inform

183 firefighting efforts. In addition to affecting air quality directly, aerosols from fires absorb and

184 scatter solar radiation and provide condensation nuclei for clouds, impacting weather forecast

185 parameters (e.g., surface temperature, precipitation), public health, life, property, and climate ${ }^{46,47}$.

186 Emissions amounts, rather than their temporal distribution, are the primary drivers of model

187 uncertainty in $\mathrm{O}_{3}$ production from wildfire emissions. Uncertain mass fluxes from satellite-based

188 emissions inventories are primarily the result of uncertain ecosystem types. The higher measured

$189 \alpha$ values than in the literature for the savannah and extratropical forest fuels present in the Oct.

1902017 N. CA fires could indicate an additional organic soil contribution to emissions. The FCCS

191 contains a more detailed fuel type classification than used in most of the satellite-based emissions

192 algorithms, and indicates that one of the Oct. 10, 2017 fuel types burned was Redwood-Tanoak

193 forest, which contains organic soils. More flux measurements are needed to establish a robust

194 relationship between CO emissions and satellite FRE, and to assess the variability of $\alpha$ for different

195 fuel types and burn conditions.

\section{References}

197 1. Cattau, M. E., Wessman, C., Mahood, A., \& Balch, J. K. Anthropogenic and lightning198 started fires are becoming larger and more frequent over a longer season length in the 199 U.S.A. Global Ecol. Biogeogr., 29, 668- 681 (2020). 
2. Lipner, E. M. et al. The associations between clinical respiratory outcomes and ambient wildfire smoke exposure among pediatric asthma patients at National Jewish Health, 20122015. GeoHealth, 3, 146- 159 (2019).

3. Pratt, J.R. et al. A national burden assessment of estimated pediatric asthma emergency (2019).

4. Abdo, M. et al. Impact of Wildfire Smoke on Adverse Pregnancy Outcomes in Colorado, 2007-2015. Int. J. Environ. Res. Public Health, 16, 3720 (2019).

5. Yue, X., \& Unger, N. Fire air pollution reduces global terrestrial productivity. Nat. Commun. 9, 5413 (2018).

6. Johnston, F. H. et al. Estimated global mortality attributable to smoke from landscape fires, Environ. Health Per., 120, 695-701 (2012).

7. Kaiser, J. W. et al. Biomass burning emissions estimated with a global fire assimilation system based on observed fire radiative power. Biogeosciences 9, 527-554 (2012)

8. Petrenko, M. et al. The use of satellite-measured aerosol optical depth to constrain biomass burning emissions source strength in the global model GOCART, J. Geophys. Res., 117, D18212, (2012).

9. Pereira, G. et al. Assessment of fire emission inventories during the South American Biomass Burning Analysis (SAMBBA) experiment. Atmospheric Chemistry and Physics 16, 6961- 6975 (2016). 
10. Young, P. J., et al. Tropospheric Ozone Assessment Report: Assessment of global-scale model performance for global and regional ozone distributions, variability, and trends. Elem Sci Anth, 6, 10 (2018).

11. Koplitz, S. N., Nolte, C. G., Pouliot, G. A., Vukovich, J. M., \& Beidler, J. Influence of Uncertainties in Burned Area Estimates on Modeled Wildland Fire PM2.5 and Ozone Pollution in the Contiguous U.S., Atmos. Environ., 191, 328-339 (2018).

12. CalFire. Top 20 Most Destructive California Wildfires. https://www.fire.ca.gov/media/5511/top20_destruction.pdf (2019).

13. Nauslar, N. J., Abatzoglou, J. T., \& Marsh, P. T. The 2017 North Bay and Southern California Fires: A Case Study. Fire, 1, 18 (2018).

14. Mass, C. F. \& Ovens, D. The Northern California Wildfires of 8-9 October 2017: The Role of a Major Downslope Wind Event. Bull. Amer. Meteor. Soc., 100, 235-256 (2019)

15. Alrick, D. The October 2017 North Bay Fires: Applying New Observational and Prediction Tools to Smoke and Air Quality Forecasting. Annual Meeting, Phoenix, AZ, American Meteorological Society, TJ19.6 (2019).

16. California Department of Forestry and Fire Protection. CAL FIRE Investigators Determine the Cause of the Tubbs Fire. https://www.fire.ca.gov/media/5124/tubbscause1v.pdf (2019)

17. Guzman-Morales, J., \& Gershunov, A. Climate change suppresses Santa Ana winds of Southern California and sharpens their seasonality. Geophysical Research Letters, 46, 2772- 2780 (2019).

18. Moritz M. A. et al. Climate change and disruptions to global fire activity. Ecosphere 3, 1$22(2012)$. 
19. Flannigan M., et al. Global wildland fire season severity in the 21 st century. For. Ecol. Manage. 294, 54-61 (2013) .

20. Yue, X., Mickley, L. J., Logan, J. A., \& Kaplan, J. O. Ensemble projections of wildfire activity and carbonaceous aerosol concentrations over the western United States in the mid21st century. Atmos. Environ. 77, 767-780 (2013) .

21. Mann, M. L. et al. Incorporating anthropogenic influences into fire probability models: Effects of human activity and climate change on fire activity in California. PLoS One 11(4):e0153589 (2016).

22. Hammer, R. B., Stewart S. I., \& Radeloff V. C. Demographic trends, the wildland-urban interface, and wildfire management. Soc. Nat. Res. 22, 777-782 (2009).

23. Liu, J.C. et al. Particulate air pollution from wildfires in the Western US under climate change. Clim. Change 138, 655-666 (2016).

24. Wu, X., Nethery, R. C., Sabath, B. M., Braun, D., \& Dominici, F. Exposure to air pollution and COVID-19 mortality in the United States: A nationwide cross-sectional study. medRxiv 2020.04.05.20054502. Preprint at https://doi.org/10.1101/2020.04.05.20054502 (2020).

25. Henderson, S. B. The COVID-19 Pandemic and Wildfire Smoke: Potentially Concomitant Disasters. American Journal of Public Health 110, 1140_1142, (2020).

26. Kille, N. et al. The CU mobile Solar Occultation Flux instrument: structure functions and emission rates of $\mathrm{NH}_{3}, \mathrm{NO}_{2}$ and $\mathrm{C}_{2} \mathrm{H}_{6}$. Atmos. Meas. Tech., 10, 373-392 (2017).

27. Baidar, S. et al. Development of a digital mobile solar tracker, Atmos. Meas. Tech., 9, 963264 972 (2016). 
28. Kille, N. et al. Separation of methane emissions from agricultural and natural gas sources in the Colorado Front Range. Geophysical Research Letters, 46, 3990-3998 (2019).

29. Mellqvist, J. et al. Measurements of industrial emissions of alkenes in Texas using the solar occultation flux method. J. Geophys. Res., 115, D00F17 (2010).

30. Ibrahim, O., et al. Car MAX-DOAS measurements around entire cities: quantification of NOx emissions from the cities of Mannheim and Ludwigshafen (Germany). Atmos. Meas. Tech., 3, 709-721 (2010).

31. National Aeronautics and Space Administration, Visible Infrared Imaging Radiometer Suite (VIIRS) 375 m Active Fire Detection and Characterization Algorithm Theoretical

32. Justice, C.O et al. The MODIS fire products. Remote Sensing of Environment, 83, 244-262 (2002).

33. Atwood, E. C. et al. Detection and Characterization of Low Temperature Peat Fires during the 2015 Fire Catastrophe in Indonesia Using a New High-Sensitivity Fire Monitoring Satellite Sensor (FireBird). PloS one, 11, e0159410 (2016).

34. Hodshire, A. L. et al. More than emissions and chemistry: Fire size, dilution, and background aerosol also greatly influence near-field biomass burning aerosol aging. Journal of Geophysical Research: Atmospheres, 124, 5589-5611 (2019).

35. Riggan, P. J. et al. Remote Measurement of Energy and Carbon Flux from Wildfires in Brazil. Ecological Applications, 14, 855-872 (2004).

36. Grell, G. A. et al. Fully coupled "online" chemistry within the WRF model, Atmos. Environ., 39, 6957-6975 (2005). 
37. Fast, J. D. et al. Evolution of ozone,particulates, and aerosol direct radiative forcing in the vicinity of Houston using a fully coupled meteorology-chemistry-aerosol model, $J$. Geophys. Res., (2006), D21305 (2006).

38. Air Sciences, Inc., Western Governors Association / Western Regional Air Partnership / Fire Emissions Joint Forum. Integrated Assessment Update and 2018 Emissions Inventory for Prescribed Fire, Wildfire, and Agricultural Burning. https://www.wrapair.org/forums/fejf/documents/emissions/WGA2018report20051123.pd $\underline{\mathrm{f}}(2018)$.

39. Li, F., Zhang, X., Kondragunta, S., \& Csiszar, I. Comparison of fire radiative power estimates from VIIRS and MODIS observations. Journal of Geophysical Research: Atmospheres, 123, 4545-4563 (2018).

40. Ottmar, R. D., Sandberg, D. V., Riccardi, C. L., Prichard, S. J. An overview of the Fuel Characteristic Classification System - Quantifying, classifying, and creating fuelbeds for resource planning. Canadian Journal of Forest Research, 37, 2383-2393, (2007).

41. Longo, K. M. et al. The Coupled Aerosol and Tracer Transport model to the Brazilian developments on the Regional Atmospheric Modeling System (CATT-BRAMS) - Part 2:

42. Wiedinmyer, C. et al. The Fire INventory from NCAR (FINN): a high resolution global model to estimate the emissions from open burning, Geosci. Model Dev., 4, 625-641, (2011).

43. Larkin, N. K. et al. The BlueSky smoke modeling framework. International Journal of Wildland Fire 18, 906-920 (2009). 
311 44. Jaffe, D. A., \& Wigder, N. L. Ozone production from wildfires: a critical review. Atmos.

$312 \quad$ Environ. 51, 1-10 (2012).

313 45. Baker, K. R., et al. Photochemical model evaluation of 2013 California wild fire air quality

314 impacts using surface, aircraft, and satellite data. Sci. Total Environ. 637-638, 1137-1149

$315 \quad$ (2018).

316 46. Grell, G., Freitas, S. R., Stuefer, M., \& Fast, J. Inclusion of biomass burning in WRF-

317 Chem: impact of wildfires on weather forecasts. Atmos. Chem. Phys., 11, 5289-5303 $318 \quad$ (2011).

319 47. Grell, G. A. \& Freitas, S. R. A scale and aerosol aware stochastic convective 320 parameterization for weather and air quality modeling. Atmos. Chem. Phys., 14, 5233-5250 $321 \quad$ (2014).

322 48. Andreae, M. O. Emission of trace gases and aerosols from biomass burning - an updated 323 assessment. Atmos. Chem. Phys., 19, 8523-8546 (2019). 
325 Table 1. Pyrogenic CO emissions based on CU AirSOF measurements, and conversion factors of

326 FRP to $\mathrm{CO}$ emissions and fuel burned, at the $\mathrm{T} 1$ and $\mathrm{T} 2$ emissions times.

\begin{tabular}{|c|c|c|c|c|c|c|c|}
\hline & \multirow{2}{*}{$\begin{array}{l}\text { AirSOF CO } \\
\text { emissions } \\
\left(\text { tonnes } \mathrm{hr}^{-1} \text { ) }\right.\end{array}$} & \multicolumn{2}{|l|}{$\operatorname{FRP}\left(\mathrm{J} \mathrm{s}^{-1}\right)$} & \multicolumn{2}{|c|}{$\alpha\left(\mathrm{g} \mathrm{CO} \mathrm{MJ}^{-1}\right)$} & \multicolumn{2}{|c|}{$\beta\left(\mathrm{kg} \text { dry matter } \mathrm{MJ}^{-1}\right)^{\mathrm{a}}$} \\
\hline & & $\begin{array}{l}\text { GOES-16 } \\
(15 \mathrm{~min} . \\
\text { mean) }\end{array}$ & MODIS & GOES-16 & MODIS & GOES-16 & MODIS \\
\hline $\mathrm{T} 1$ & $425 \pm 137$ & $7.07 \times 10^{8}$ & --- & $167 \pm 54$ & --- & $2.42 \pm 0.78$ & --- \\
\hline $\mathrm{T} 2$ & $2040 \pm 316$ & $3.80 \times 10^{9}$ & $7.78 \times 10^{9}$ & $149 \pm 23$ & $73 \pm 11$ & $2.16 \pm 0.33$ & $1.06 \pm 0.16$ \\
\hline
\end{tabular}

$327{ }^{\mathrm{a}} \mathrm{CO} \mathrm{EF}$ of $69 \mathrm{~g} \mathrm{~kg}^{-1}$, the mean value for savannah/grassland ${ }^{48}$, was used.

328 


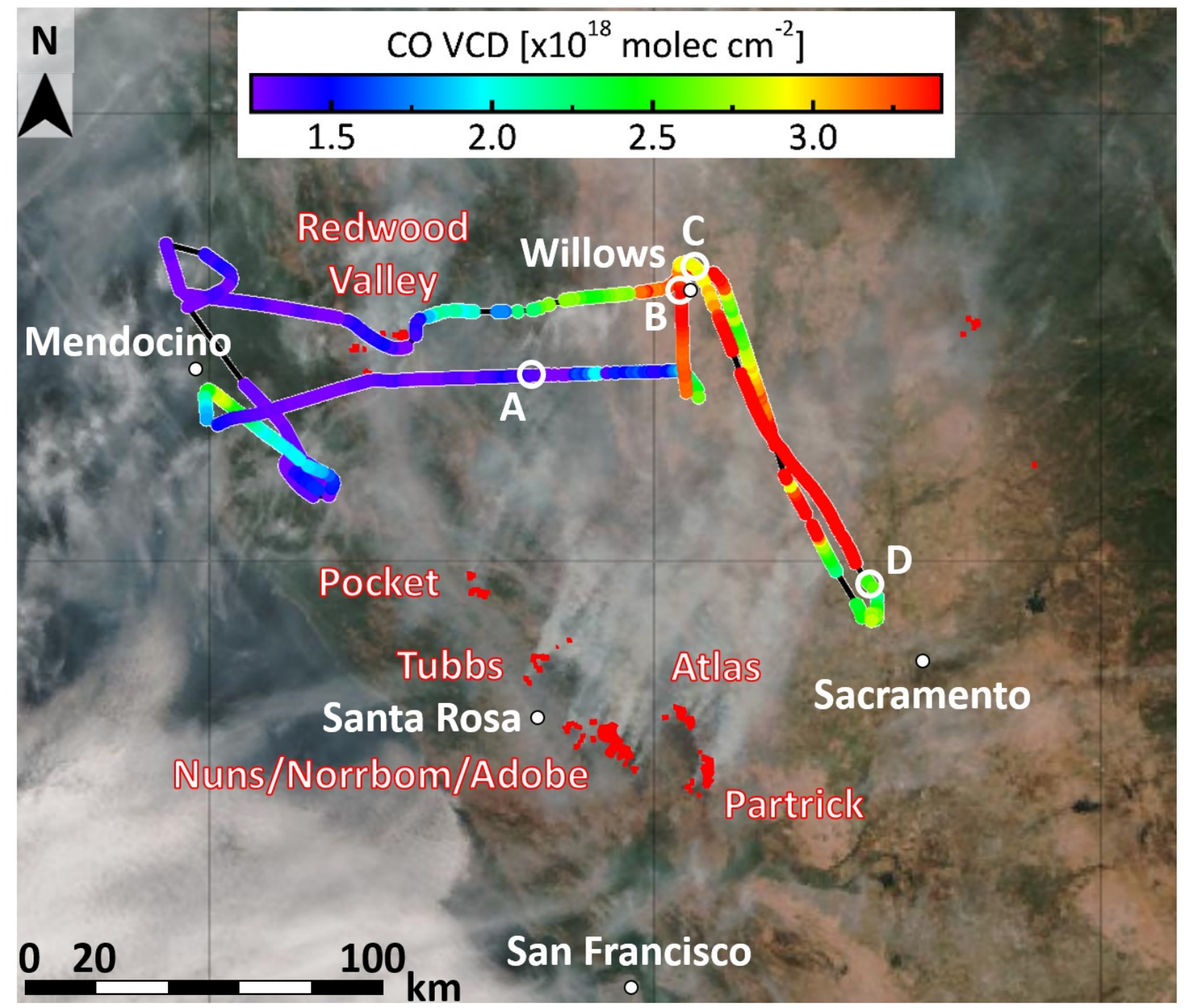

330 Figure 1. Quantifying CO emissions from the Northern California Fires using CU AirSOF

331 on 10 Oct 2017. Flight track color coded with CO VCDs measured by CU AirSOF, overlaid on

332 VIIRS satellite image (14:11 PDT). White dots indicate cities; red dots mark fire locations; white

333 open circles mark the locations of corresponding labels shown in Figure 2. 


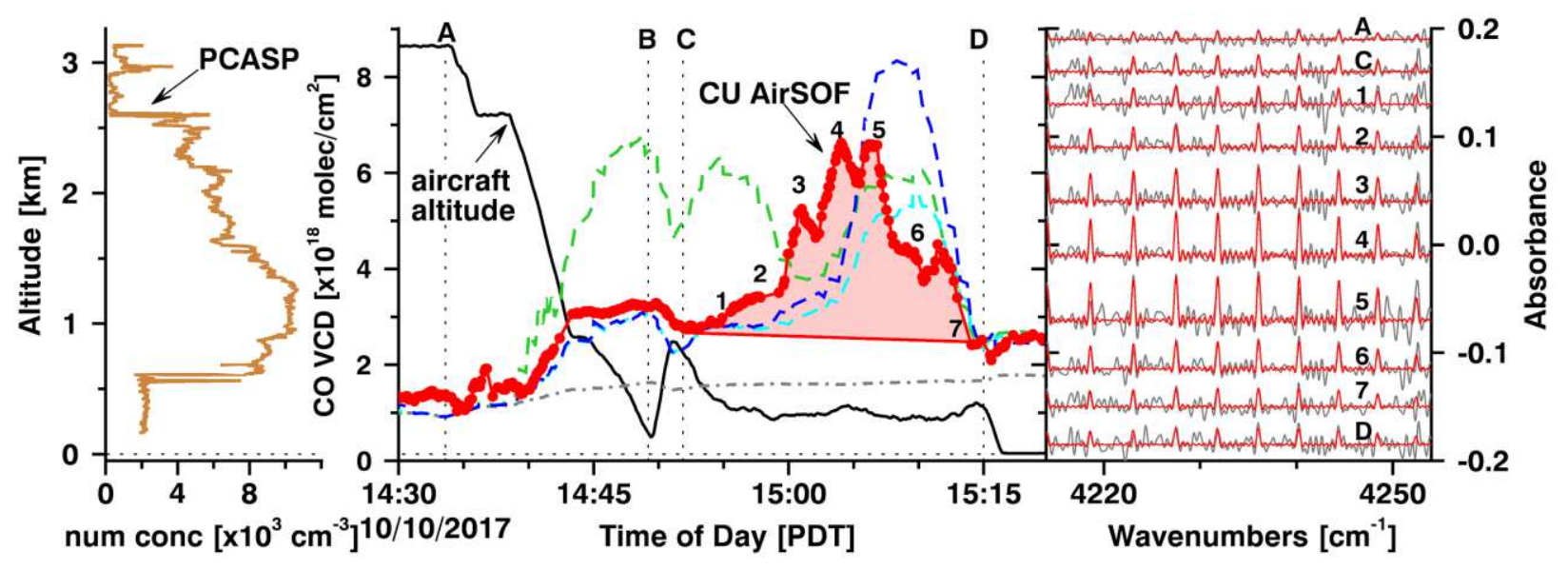

335 Figure 2. CO flux measurements and spectral proof. Left: Vertical plume profile near Willow,

336 CA. Center: measured CO (red) and predicted CO by four WRF-Chem model simulations: (1) no

337 pyrogenic emissions (gray); (2) constant emission flux (green), taken as the measured flux during

338 T2; emissions constrained by CU AirSOF flux using (3) climatological (blue) and (4) GOES-16

339 (cyan) diurnal cycles. Right: Spectral proof of CO fingerprint absorption outside the plume (A, D)

340 and inside the plume (1-7), showing the scaled CO reference spectrum (red) overlaid the residual

341 noise (grey). Waypoints A-B: vertical profile; C-D: flux measurement period T2 (see Figure 1). 

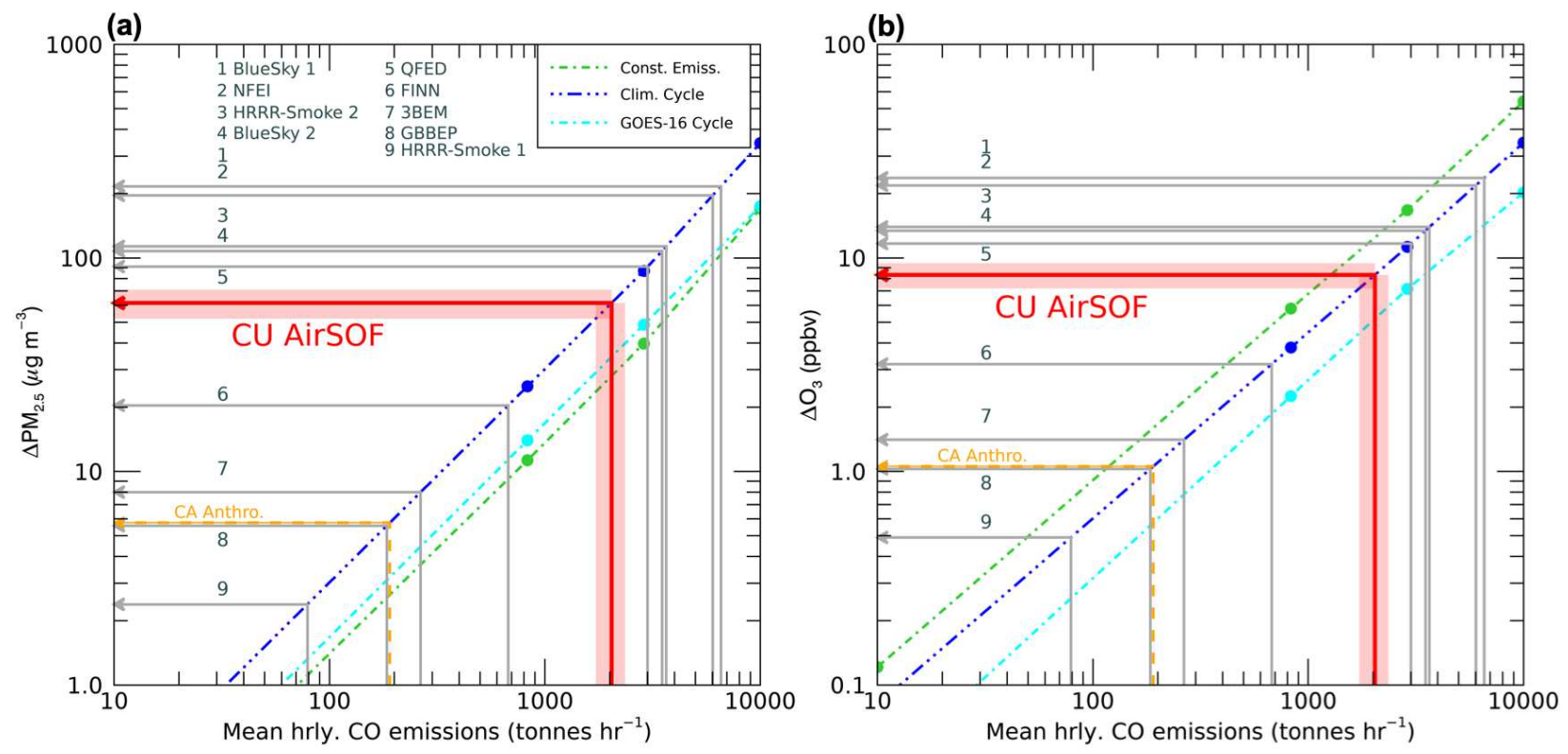

344 Figure 3: Air quality impacts of pyrogenic emissions, and comparison with other pollution

345 sources in California. The measured $\mathrm{CO}$ emission flux ("CU AirSOF" for T2 with error bars)

346 compared with hourly mean pyrogenic $\mathrm{CO}$ emission estimates from bottom-up and top-down

347 satellite-based inventories (gray lines), and California 2017 mean anthropogenic CO emissions

348 (orange dashed lines). Air quality implications of uncertainties in the hourly fire emissions are

349 quantified as (a) $\mathrm{PM}_{2.5}$ and (b) $\mathrm{O}_{3}$ enhancements (mean PBL changes at 3 p.m. PDT on 10 Oct

3502017 ) simulated by WRF-Chem using constant and diurnally varying fire emissions. 


\section{CU AirSOF instrument and emissions estimates}

353 Pre-BB-FLUX (Preliminary instrument testing for the Biomass Burning Fluxes of Trace Gases

354 and Aerosol field campaign; http://flights.uwyo.edu/projects/prebbflux17/) took place in Fall

355 2017. The University of Wyoming King Air (UWKA) research aircraft was equipped with the CU

356 AirSOF instrument (Kille et al., 2017) and standard in-situ observations. Focused testing of CU

357 AirSOF in biomass burning smoke took place on Oct. 10, 2017, targeting the smoke from the Oct.

3582017 wildfires in N. CA described in this work. The aircraft conducted two plume underpasses in

359 the Central Valley at distances of $\sim 60-100 \mathrm{~km}$ downwind of the fires.

360 The CU AirSOF instrument uses a custom-built digital solar tracker ${ }^{27}$ and is described in detail

361 for a ground-based mobile application to quantify emissions from area sources by mass balance

362 using vertical column density (VCD) measurements ${ }^{26}$. CO is retrieved from CU AirSOF solar

363 spectra $\left(700-5000 \mathrm{~cm}^{-1}\right)$ using the spectral region at $4215-4254 \mathrm{~cm}^{-1}$. Spectral proof of the

364 detection of CO is shown in Extended Data Figure E1. Solar absorption measurements offer good 365 sensitivity in the vertical column across the whole atmosphere as shown in Extended Data Figure 366 E2.

367 The $\mathrm{CO}$ emission flux is calculated using Equation 1 for each plume underpass. Background 368 CO VCD are measurements taken south of the sharp plume gradient. For T2, Extended Data Figure 369 E5 indicates models determine the airmass after 15:15 PDT is older and considered background.

370 For T2, the wind is determined from the profile flown prior to 14:50 PDT into Willows (see Figures 371 and 2); wind speed and direction measurements were weighted by the vertical plume distribution 
372 that is indicated by Passive Cavity Aerosol Spectrometer Probe (PCASP) particle number

373 concentration, measured aboard the UWKA aircraft.

374 Winds and humidity measurements were collected aboard the UWKA aircraft and used to

375 evaluate the model ability to simulate meteorology in the fire region. PCASP aerosol number was

376 converted to aerosol mass concentrations, using a typical biomass burning aerosol density of $1 \mathrm{~g}$

$377 \mathrm{~cm}^{-3}$, to compare with simulated aerosol profiles.

378 Satellite-based fire emissions inventories

379 Emissions were generated with PREP-CHEM-SRC ${ }^{49}$, using the Brazilian Biomass Burning 380 Emission Model (3BEM) $)^{41}$ based on Wildfire Automated Biomass Burning Algorithm 381 (WFABBA) and MODIS fire count data. Emissions were also obtained from the following 382 inventories, which vary in the satellite products used (e.g. fire detections versus FRE): the Fire 383 INventory from NCAR (National Center for Atmospheric Research) (FINN) v1. $5^{42}$; United States 384 Forest Service (USFS) Bluesky ${ }^{43}$; the 2017 National Fire Emissions Inventory (NFEI) ${ }^{50}$; the 385 HRRR-Smoke BB flux scheme ${ }^{51}$ (used in the NOAA/ESRL High-Resolution Rapid Refresh 386 (HRRR)-Smoke forecasts); the NASA Quick Fire Emissions Dataset (QFED) ${ }^{52}$; and the 387 NOAA/National Environmental Satellite, Data, and Information Service (NESDIS) experimental 388 global biomass burning emission product $(\mathrm{GBBEPx})^{53}$. Satellite fire datasets utilized in inventories 389 are given in Extended Data Table E1. The first USFS Bluesky estimate used HMS fire location 390 data (GOES-15, VIIRS, MODIS). The second estimate used GOES-16 fire location data, and 391 GEOMAC fire perimeter information to constrain the area estimates and also the hot spot locations 392 and is lower than the first, primarily due to smaller burned areas. The first HRRR-Smoke emissions 393 estimate is the developmental version generated Oct. 10, 2017 for the real-time HRRR-Smoke 
394 forecast. The second HRRR-Smoke emissions estimate was generated Oct. 15, 2018 with an

395 updated version of the real-time emissions code, which is being transitioned to the operational

396 system at NOAA/NCEP. Both the HRRR-Smoke and BlueSky preliminary and second more-

397 refined estimates reflect a dialing-in of estimates as more information becomes available and

398 systems continually improve. Initial estimates differed quite a bit, while the second set of estimates

399 were quite similar. These systems also illustrate the similarities and differences between using a 400 ground-based and remotely-sensed based system to quantify fuels information. BlueSky relies on

401 the FCCS to estimate the vegetation burned. Fuel heterogeneity, natural to the landscape, can 402 account for more than an order of magnitude variability in emissions estimated. In the case of the 4032017 Northern California wildfires, they burned through approximately 10 different vegetation 404 types with fuel loadings ranging from $1-160$ tons acre ${ }^{-1}$. On October 10, 2017, approximately $8 \%$ 405 of the acres burned in a Redwood-Tanoak forest which resulted in $57 \%$ of the CO emissions. This 406 heavy fuel type had a significant portion of large woody fuels and duff, both of which burn in the 407 smoldering phase of combustion.

408 Additional details about the satellite-based emissions inventories are contained in the 409 Supplementary Information.

\section{WRF-Chem simulation setup}

411 WRF-Chem simulations were conducted from 5 a.m. LT on Oct. 9, 2017 to 11 p.m. LT on 412 Oct. 10, 2017 (0 UTC on Oct. 10, 2017 to 6 UTC on Oct. 11, 2017).

413 A domain with $4 \mathrm{~km}$ horizontal grid spacing covering the N. CA fire region (southwest corner:

$41437.86^{\circ} \mathrm{N}, 123.46^{\circ} \mathrm{W}$, northeast corner: $41.05^{\circ} \mathrm{N}, 122.23^{\circ} \mathrm{W}$ ) was nested off-line with half-hourly 
415 output from a $12 \mathrm{~km}$ horizontal grid spacing domain that covered the Western U.S. (southwest 416 corner: $29.32^{\circ} \mathrm{N}, 124.35^{\circ} \mathrm{W}$, northeast corner: $\left.58.60^{\circ} \mathrm{N}, 93.98^{\circ} \mathrm{W}\right)$. Both domains contained 51

417 vertical levels with a model top of $50 \mathrm{hPa}(\mathrm{ca} .20 .7 \mathrm{~km})$, with vertical grid spacing ranging from $41821 \mathrm{~m}$ in the first model level above the ground to $150 \mathrm{~m}$ in the upper part of the boundary layer 419 and 500-700 $\mathrm{m}$ in the upper troposphere. Only results from the $4 \mathrm{~km}$ domain are shown and 420 discussed in this paper. Meteorological initial and boundary conditions were obtained from the 421 North American Mesoscale Analysis (NAM-ANL) with a 6 hourly time resolution and $12 \mathrm{~km}$ 422 horizontal grid spacing. Various meteorology inputs were tested using a meteorology-only (WRF) 423 configuration (European Centre for Medium-Range Weather Forecasts (ECMWF) Re-Analysis 424 Interim (ERA-Interim), Global Forecast System (GFS), Rapid Refresh (RAP)), but the NAM ANL 425 was chosen for the WRF-Chem simulations to minimize wind speed and direction bias (Extended 426 Data Figure E6). Vertical profiles of meteorological variables are compared for meteorology-only $4274 \mathrm{~km}$ WRF simulations with initial and boundary conditions from RAP, NAM-ANL, GFS, and 428 ERA-Interim in Extended Data Figure E7.

429 Chemical and initial boundary conditions were provided by idealized profiles for North 430 American summer. Anthropogenic emissions were generated from the 2011 National Emissions 431 Inventory $(\mathrm{NEI})^{54}$. Biogenic emissions were calculated online by the Model of Emissions of Gases 432 and Aerosols from Nature (MEGAN) v2.04 ${ }^{55}$. Gas phase and aerosol chemistry with aerosol433 radiation interactions were represented with the RACM-MADE-VBS mechanism ${ }^{56}$. No aerosol434 microphysics interactions were included.

435 A pair of tracers, one passive and one with a constant chemical lifetime, with the same 436 emissions as $\mathrm{CO}$, were used to calculate time from emission $(t, \mathrm{~s})$ as follows: 
$437 \quad(5) t=-\tau \cdot \ln \left(\frac{C_{A}}{C_{N A}}\right)$

438 where $\tau$ is the rate of decay $\left(\mathrm{s}^{-1}\right)$ and $C_{A}$ and $C_{N A}$ are the mixing ratios (ppbv) of the aging and non439 aging tracers, respectively. Column average time from emission for T2 is depicted in Extended $440 \quad$ Data Figure E5.

441 Fire emissions were first generated for the WRF-Chem grid with 3BEM. Total emissions of 442 gases and aerosols within the Oct. 2017 N. CA fire region were scaled by the CU AirSOF CO 443 emissions estimate of 2040 tonnes $\mathrm{hr}^{-1}$ from the T2 plume sampling period at the emissions time 444 based on an airmass age in the center of the T2 plume of 2.5 hours determined from the WRF445 Chem aging tracers, and EFs from the literature ${ }^{57,58}$. Fire emissions within the Oct. 2017 N. CA 446 fire region were spatially distributed according to GOES-16 FRE integrated for the $30 \mathrm{hr}$ 447 simulation period (Extended Data Figure E3). The model emissions were temporally distributed 448 either by a constant rate of 2884 tonnes $\mathrm{hr}^{-1}$ (calculated by integrating the climatological cycle for 449 the first 24 hours, with the emissions at the T2 emissions time equal to the CU AirSOF 450 estimate, then dividing by 24 hours), or by setting $\mathrm{CO}$ emissions at the $\mathrm{T} 2$ emissions time to the 451 CU AirSOF estimate of 2040 tonnes $\mathrm{hr}^{-1}$ and extrapolating emissions at other times using the 452 climatological cycle (Extended Data Figure E3).

453 Two $4 \mathrm{~km}$ model simulations with the same total daily emissions were conducted, one with 454 constant emissions at each time step, and one with the climatological diurnal cycle ${ }^{38}$ depicted in 455 Extended Data Figure E3. The $4 \mathrm{~km}$ constant emission simulation used initial and boundary 456 conditions from the $12 \mathrm{~km}$ simulation with diurnally varying emissions. 
The injection height calculation in the WRF-Chem simulations uses a one-dimensional plume

458 rise model $^{59}$ with heat flux and convective energy calculated from mean daily FRE. The injection

459 height calculation was not altered in a time varying manner according to GOES-16 FRE, as plume

460 rise height is a function of heat flux (the ratio of FRP fire size), which is approximately constant

461 since FRE and fire size follow similar diurnal cycles.

462 The model emissions error budget (Extended Data Table E2) was calculated as follows (terms

463 from Equation 3). The uncertainty $(\delta)$ in $E F, \delta E F$, is given by the standard deviation in the $\mathrm{CO}$

464 EFs provided in a literature review ${ }^{48} . \delta F R E$ is the uncertainty introduced by the transport time

465 calculated from the WRF-Chem simulations (e.g. errors in simulated wind fields), and is estimated

466 here as the percent difference between the following quantity calculated from simulations with

467 constant and climatological diurnal emissions cycles: total column CO from the simulation with

468 fire emissions minus total column $\mathrm{CO}$ from the simulation without fire emissions, integrated over

469 the T2 sampling period (Figure 2).

$470 \quad$ (6) $V C D_{\text {fire }}=\left(V C D_{\text {with fire }}-V C D_{\text {without fire }}\right)$

$471 \quad$ (7) $\delta F R E=100 * \frac{\left(V C D_{\text {fire }}\right)_{\text {clim }}-\left(V C D_{\text {fire }}\right)_{\text {const }}}{\left(V C D_{\text {fire }}\right)_{\text {const }}}$

$472 \delta \beta$ is estimated from the range of $\beta$ values calculated from different satellites and the upper 473 and lower ranges of CU AirSOF measurements (Table 1).

\section{Data and Code Availability}

475 The CU AirSOF $\mathrm{CO}$ dataset is available upon reasonable request to $\mathrm{R}$. Volkamer 476 (rainer.volkamer@,colorado.edu). The in-situ dataset generated during the Pre-BB-FLUX 
477 campaign are available from University of Wyoming - Research Flight Center, 2018: Flight Level

478 Data from the University of Wyoming King Air during the Preliminary instrument testing for the 479 Biomass Burning Fluxes (Pre-BB-FLUX) project, Version 1.0. University of Wyoming, College 480 of Engineering, Department of Atmospheric Science,_doi:10.15786/g9zh-8997, 481 http://flights.uwyo.edu/projects/prebbflux17/. NEI and NFEI 2017 emissions were obtained from 482 https://www.epa.gov/air-emissions-inventories/2017-national-emissions-inventory-nei-data.

483 QFED $\quad$ emissions $\quad$ were $\quad$ obtained from $484 \mathrm{ftp} / / / \mathrm{ftp} . n c c s . n a s a . g o v /$ aerosol/emissions/QFED/v2.5r1/0.1/QFED/Y2017/M10/. (the MODIS 485 data can be obtained from https://earthdata.nasa.gov/earth-observation-data/near-real-time/firms). 486 NAM meteorological data were obtained from 487 https://www.ncdc.noaa.gov/has/HAS.FileAppRouter?datasetname=NAMANL218\&subqueryby= 488 STATION\&applname=\&outdest=FILE and ERA-Interim from http://apps.ecmwf.int/datasets/ 489 data/interim-full-daily/levtype $=\mathrm{pl} /$. WRF-Chem model output is available upon reasonable request 490 to M.M. Bela (megan.bela@noaa.gov).

\section{Methods References}

492 49. Freitas, S. R. et al. PREP-CHEM-SRC - 1.0: a preprocessor of trace gas and aerosol 493 emission fields for regional and global atmospheric chemistry models. Geoscientific Model $494 \quad$ Development 4, 419-433 (2011).

495 50. U.S. Environmental Protection Agency Office of Air Quality Planning and Standards, Air 496 Quality Assessment Division, Emissions Inventory and Analysis Group, Research Triangle 497 Park, North Carolina. 2017 National Emissions Inventory Complete Release Technical 

04/documents/nei2017 tsd_full_30apr2020.pdf (2020).

51. Ahmadov, R. et al. Using VIIRS fire radiative power data to simulate biomass burning emissions, plume rise and smoke transport in a real-time air quality modeling system. 2017 IEEE International Geoscience and Remote Sensing Symposium (IGARSS), Fort Worth, TX, 2017, 2806-2808 (2017). https://ntrs.nasa.gov/archive/nasa/casi.ntrs.nasa.gov/20180005253.pdf (2015). global biomass burning emissions product from geostationary satellite constellation. Journal of Geophysical Research: Atmospheres 117 (2012).

54. Bahreini, R., et al. Sources and characteristics of summertime organic aerosol in the Colorado Front Range: perspective from measurements and WRF-Chem modeling, Atmos. Chem. Phys. , 18, 8293-8312 (2018).

56. Tuccella, P. et al. A new chemistry option in WRF-Chem v. 3.4 for the simulation of direct

55. Guenther, A. et al. Estimates of global terrestrial isoprene emissions using MEGAN (Model of Emissions of Gases and Aerosols from Nature). Atmospheric Chemistry and and indirect aerosol effects using VBS: evaluation against IMPACT-EUCAARI data. Geoscientific Model Development 8, 2749-2776 (2015).

57. Andreae, M. O. \& Merlet, P. Emission of trace gases and aerosols from biomass burning. Global Biogeochemical Cycles 15, 955-966 (2001). 
58. Yokelson, R. J. et al. Coupling field and laboratory measurements to estimate the emission factors of identified and unidentified trace gases for prescribed fires. Atmospheric Chemistry and Physics 13, 89-116 (2013).

59. Freitas, S. R., et al. Including the sub-grid scale plume rise of vegetation fires in low resolution atmospheric transport models. Atmos. Chem. Phys., 7, 3385-3398 (2007).

\section{Acknowledgements}

527 The Pre-BB-FLUX field campaign was supported by NSF awards AGS-1744537 and AGS-

5281754019 (PI: Rainer Volkamer). Natalie Kille is a recipient of a CIRES graduate fellowship. We

529 thank the Pre-BB-FLUX science team, in particular Barbara Dix and David Thomson, and the UW

530 flight center staff, in particular Matt Burkhart, Brent Glover, Ben Heesen, Bill Kuestner, Zane

531 Little, Nick Mahon, Larry Oolman, and Brett Wadsworth. R. Ahmadov and E. James thank

532 NOAA's Joint Polar Satellite System (JPSS) Proving Ground and Risk Reduction (PGRR) program

533 for funding. We also thank Gregory Frost for feedback on the manuscript. We thank Robert

534 Lipschutz (NOAA ESRL GSL) for providing the RAP and GFS meteorological data and MODIS

535 FRP, and Ivan Csiszar and Marina Tsidulko for the VIIRS FRP.

\section{Authors Contributions}

537 RV and MB designed research; NK and RV conducted field measurements; MB and SM conducted

538 model simulations; RA, EJ, GP, SO, XZ, SK, and CW contributed emissions data and modeling 539 tools; CS and RP provided satellite data; MB and NK analyzed data; MB, NK, SM, RA and RV 540 interpreted results; MB, NK, and RV wrote the paper, with contributions from all co-authors. 


\section{Competing Interests}

543 The authors declare that they have no competing financial interests.

544 Supplementary Information is available for this paper.

545 Correspondence and requests for materials should be addressed to Rainer Volkamer

546 (Rainer.Volkamer@colorado.edu) and Megan M. Bela (megan.bela@noaa.gov).

547 Reprints and permissions information is available at www.nature.com/reprints 


\section{Figures}

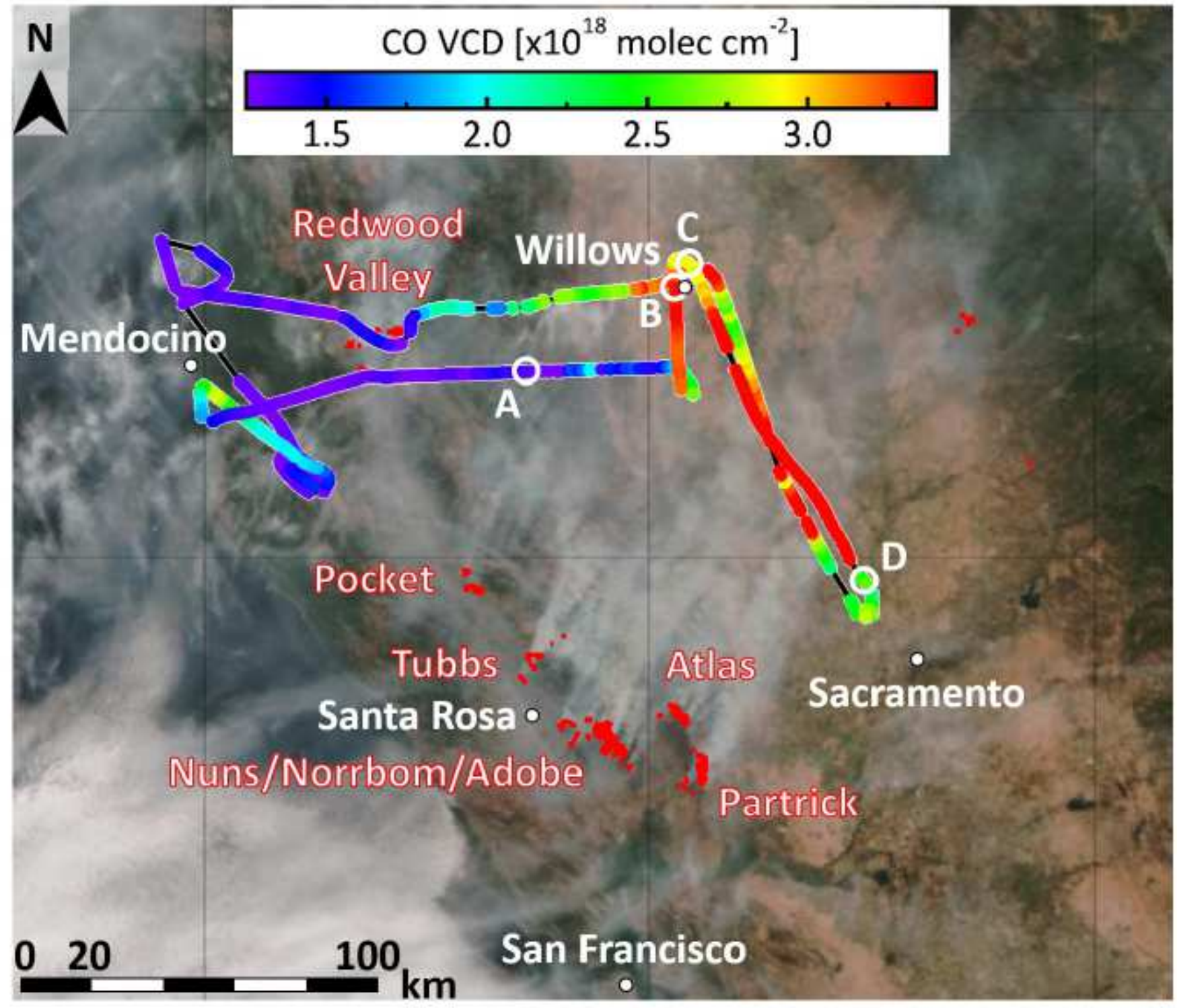

Figure 1

Quantifying CO emissions from the Northern California Fires using CU AirSOF on 10 Oct 2017. Flight track color coded with CO VCDs measured by CU AirSOF, overlaid on VIIRS satellite image (14:11 PDT). White dots indicate cities; red dots mark fire locations; white open circles mark the locations of corresponding labels shown in Figure 2. 


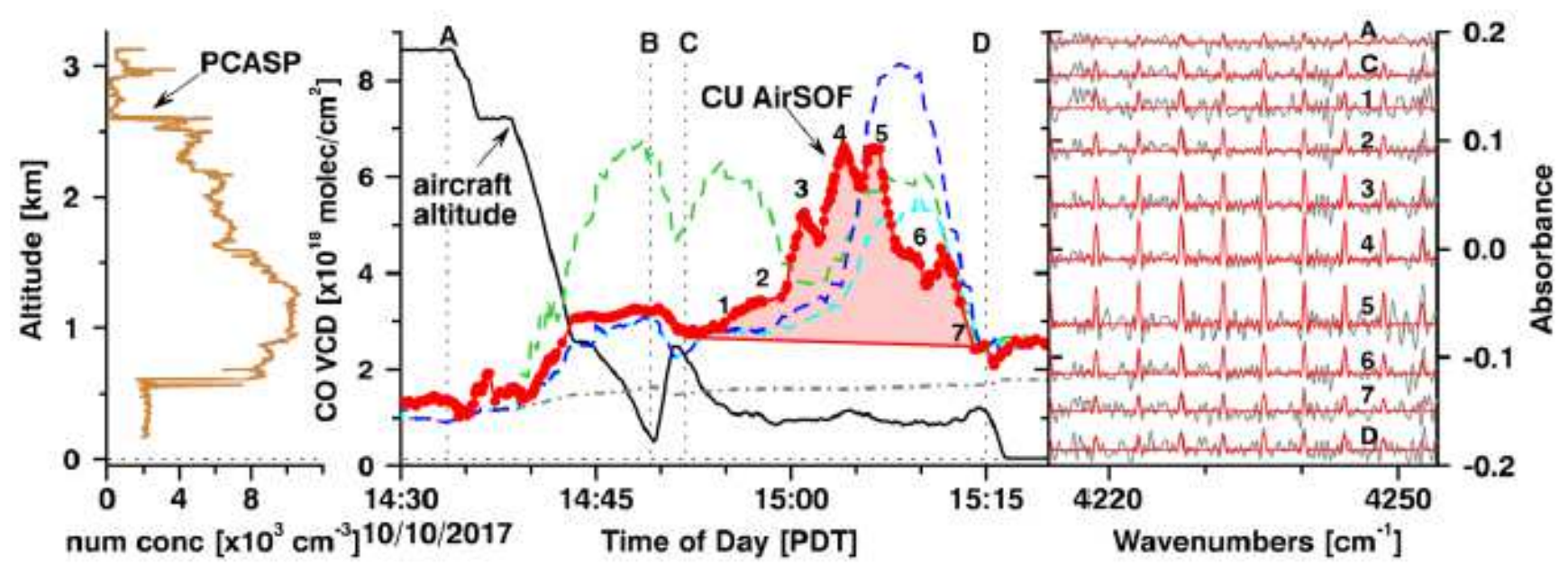

Figure 2

CO flux measurements and spectral proof. Left: Vertical plume profile near Willow, CA. Center: measured CO (red) and predicted CO by four WRF-Chem model simulations: (1) no pyrogenic emissions (gray); (2) constant emission flux (green), taken as the measured flux during T2; emissions constrained by CU AirSOF flux using (3) climatological (blue) and (4) GOES-16 (cyan) diurnal cycles. Right: Spectral proof of CO fingerprint absorption outside the plume (A, D) and inside the plume (1-7), showing the scaled CO reference spectrum (red) overlaid the residual noise (grey). Waypoints A-B: vertical profile; C-D: flux measurement period T2 (see Figure 1).
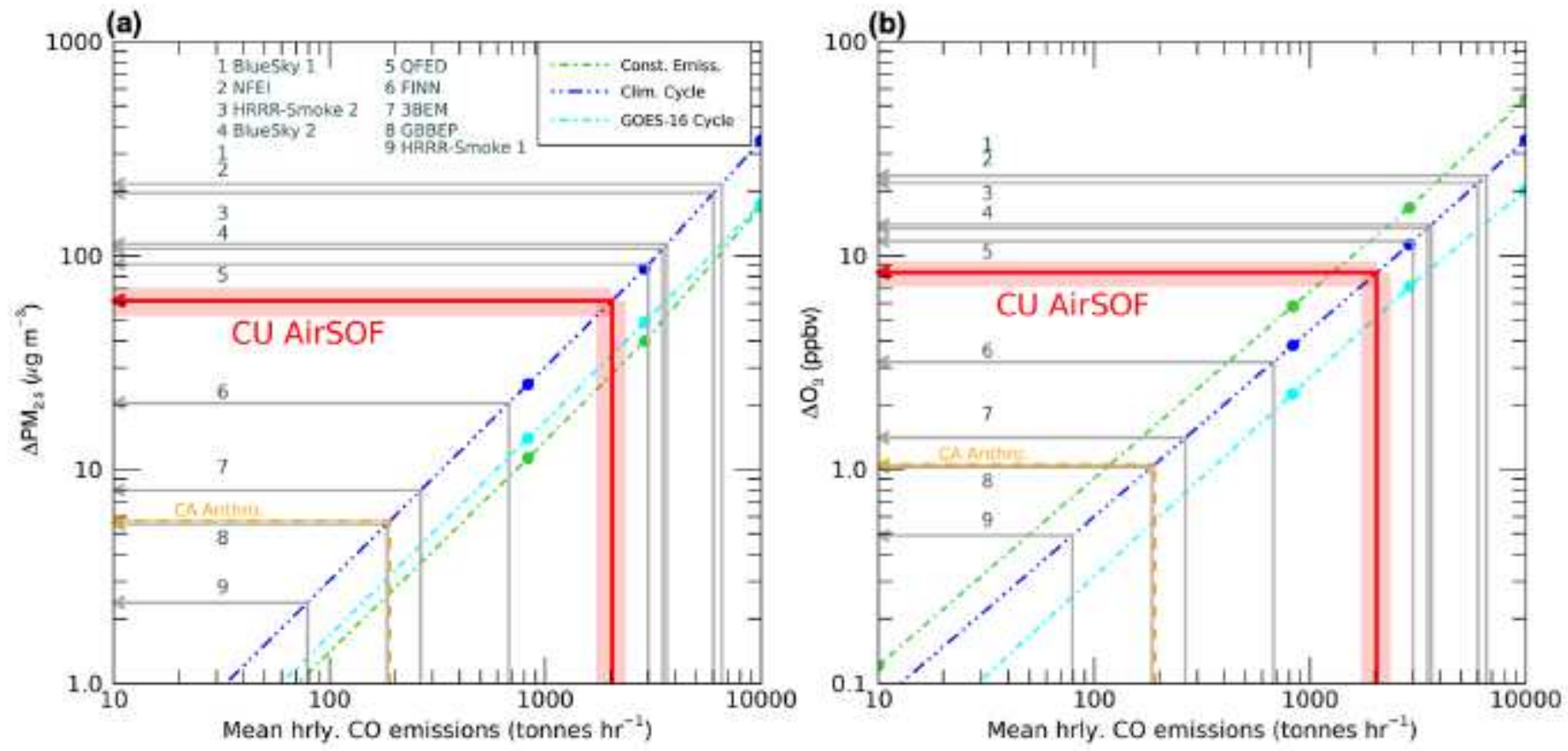

Figure 3 
Air quality impacts of pyrogenic emissions, and comparison with other pollution sources in California. The measured $\mathrm{CO}$ emission flux ("CU AirSOF" for T2 with error bars) compared with hourly mean pyrogenic $\mathrm{CO}$ emission estimates from bottom-up and top-down satellite-based inventories (gray lines), and California 2017 mean anthropogenic $\mathrm{CO}$ emissions (orange dashed lines). Air quality implications of uncertainties in the hourly fire emissions are quantified as (a) PM2.5 and (b) 03 enhancements (mean PBL changes at 3 p.m. PDT on 10 Oct 2017) simulated by WRF-Chem using constant and diurnally varying fire emissions.

\section{Supplementary Files}

This is a list of supplementary files associated with this preprint. Click to download.

- Belaetal2020ExtendedData.pdf

- Belaetal2020Supplementarylnformation.pdf 